\title{
Engineering Bacteria to Produce Pure Phage-like Particles for Gene Delivery
}

\author{
Matthew Tridgett, Maria Ababi, Alexander Osgerby, Robert Ramirez Garcia, and Alfonso Jaramillo* \\ Cite This: https://dx.doi.org/10.1021/acssynbio.0c00467 \\ Read Online
}

ACCESS |

Lلll Metrics \& More

Article Recommendations

Supporting Information

ABSTRACT: Natural and engineered phages have been used in many applications, but their use to deliver user-defined genetic cargoes has been hampered by contamination with replicative phage, restricting use of the technology beyond the laboratory. Here we present a method to produce transducing particles without contamination. In addition, we demonstrate the use of a helper phage-free transducing particle preparation as an antimicrobial agent. This will pave the way for the development of new phage-based technologies with greater scope than lytic phage therapy.

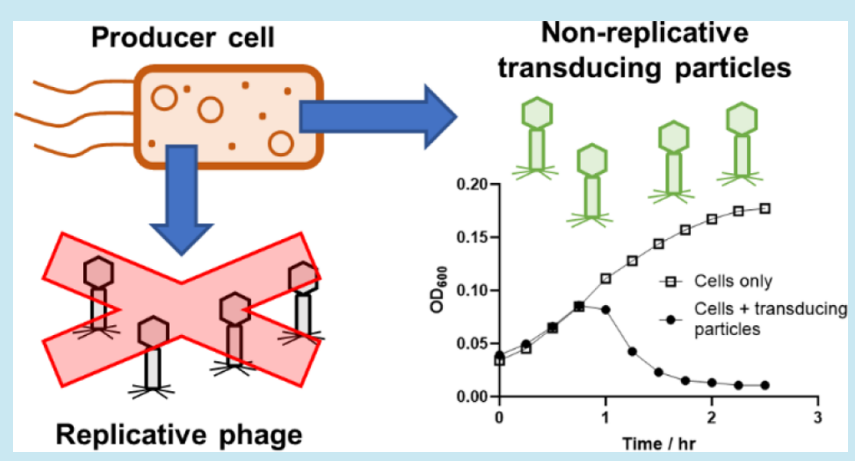

KEYWORDS: bacteriophage, transduction, cosmid, bacteriophage therapy, recombineering, cosmid

$\mathrm{T}$ ransduction is a process in which bacterial nucleic acids are transferred from one bacterial cell to another by bacteriophage structural proteins. ${ }^{1}$ The assembly comprising virion proteins and the nonbacteriophage nucleic acid cargo is called a transducing particle. In the preparation of transducing particles, structural proteins are supplied by a helper bacteriophage. Typically, cells containing the cargo to be transduced are infected with helper bacteriophage, which carries out its lytic reproductive cycle, during which, some nonbacteriophage nucleic acid is packaged into bacteriophage capsids, yielding transducing particles. Upon cell lysis, helper phage progeny and transducing particles are released, which can infect recipient cells, either continuing the helper bacteriophage lytic cycle or completing transduction, respectively.

Bacteriophage transduction has been proposed as an alternative to bacteriophage therapy in which lytic phages are used, for the following reasons: (1) Bacteriophage transduction is independent of the processes that occur within the recipient cell as there is no requirement for the interaction of host/ parasite gene networks for replication, virion assembly, and cell exit, as with native bacteriophages. ${ }^{2-4}$ Thus, the specificity of a transducing particle could be reprogrammed to new hosts solely on the basis of receptor recognition and DNA injection, without the need to identify a cognate bacteriophage, as would be required for traditional bacteriophage therapy; ${ }^{5}$ (2) As transducing particles are nonreplicative, their route to market may be simpler than that of whole bacteriophages because, clearly, the release of nonreplicative transducing particles is more easily controllable than whole bacteriophages; (3) Transduction is more flexible than bacteriophage therapy using lytic phages. While lytic bacteriophage therapy is restricted to killing bacterial cells, transduction could be used to introduce a variety of user-defined genetic constructs to bacterial cells, including antibiotic sensitization cassettes, antigens for the in situ production of vaccines, lysins to selectively kill the targeted bacteria, or biofilm-degrading enzymes, among others. Because of the many attractive features of bacteriophage transduction, it is being actively researched to develop novel technologies and is being used as a research tool. ${ }^{5-8}$ It should be noted, however, that bacteriophage transduction carries the caveat that since the particles are nonreplicative, they must be administered to the patient in higher doses than required for bacteriophage therapy using replicative lytic bacteriophages.

We are interested in P2 bacteriophage as a candidate for bacteriophage transduction for the following reason: Its nonspecific DNA injection mechanism-the step following the receptor-specific adsorption step-suggests it could be reprogrammed by mutagenesis to recognize and deliver DNA to alternative hosts - as was demonstrated with the related Rtype pyocins-broadening its range of applications. ${ }^{9-11}$

However, P2 bacteriophage, once established as a prophage, is noninducible, thus it cannot perform as a helper

Received: September 8, 2020 
A

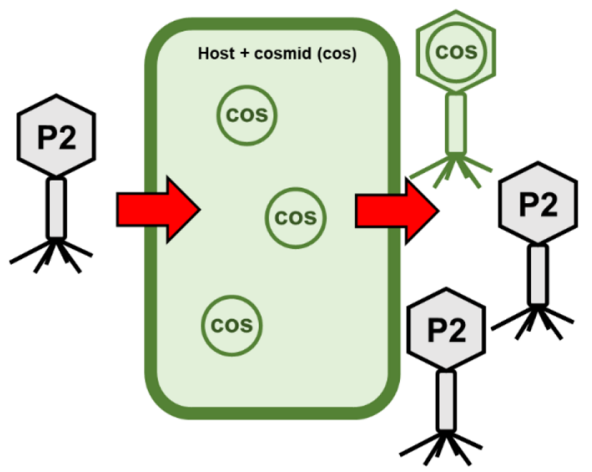

Contaminated

B
Pure

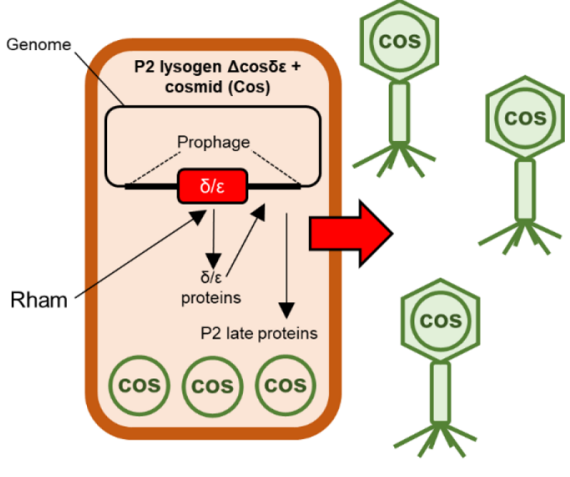

Figure 1. Comparison of methods to produce preparations of transducing particles. (A) Method using P2vir1 as the helper bacteriophage. (B) Method using Escherichia coli strain lysogenized with cos site deficient P2 prophage that encodes chemically inducible P4 bacteriophage proteins as the helper bacteriophage.

bacteriophage in transducing particle preparation, since the necessary structural proteins will not be expressed. ${ }^{12}$ Thus, the lytic variant P2vir1 must be used as a helper bacteriophage for transduction. ${ }^{13}$ However, this method yields preparations of transducing particles that are contaminated with helper bacteriophage (Figure 1A). ${ }^{14}$ Heat-inducible variants of the P2 lysogen can be used as helper bacteriophage to produce transducing particles. ${ }^{15,16}$ However, these retain the P2 packaging signal and thus retain the possibility of helper bacteriophage contamination in the transducing particle preparation.

Helper bacteriophage contamination renders transducing particle preparations unsuitable for clinical trials or pharmaceutical use, as it would be necessary to demonstrate the safety and efficacy of the transducing particles and the helper phage separately and in combination. ${ }^{17}$ If they cannot be separated, they cannot be tested in isolation.

Contamination by helper bacteriophage is not unique to the preparation of P2-derived transducing particles. Bikard et al. used the Staphylococcus aureus bacteriophage $\Phi N M 1$ as a helper bacteriophage to package a $\Phi$ NM1-derived phagemid. ${ }^{6}$ In this system, $24 \%$ of the total bacteriophage particles contained the user-defined DNA and the remaining $76 \%$ were wild-type helper bacteriophage contaminants. Because of this contamination, experiments had to be performed using an immune bacterial strain ( $\Phi$ NM1 lysogen) as the recipient strain, to prevent lysis by the contaminant.

In addition, the preparation of T7 bacteriophage-derived transducing particles yields contaminated preparations. 5,18 Yosef et al. produced transducing particles with a tail fiberdeficient variant of T7 as the helper bacteriophage. ${ }^{5}$ However, despite this measure, when delivering the cargo, the T7insensitive $E$. coli variant $\Delta \operatorname{tr} x A$ had to be used to prevent cell lysis by the helper bacteriophage contamination. Chung and Hinkle reported a $\sim 1: 1$ ratio of transducing particles to helper bacteriophage yielded by this method and removed the contamination by cesium chloride sedimentation. ${ }^{18}$ An ideal method would have no helper bacteriophage contamination in the first place.

To eliminate contamination, others have avoided helper bacteriophage altogether and opted to genetically modify a bacteriophage instead, using this to deliver genetic cargo. Edgar et al. developed a system for the sensitization of pathogenic bacteria to antibiotics, delivering genetic material to recipient cells with $\lambda$ bacteriophage-derived virions. ${ }^{19}$ The genetic material delivered contained all the information required to produce infectious virions and the user-defined genetic cargo. Furthermore, Yosef et al. modified the genome of a $\lambda$ prophage by homologous recombination. ${ }^{20}$ Upon induction of the modified prophage, bacteriophage particles were produced and later used to introduce the modified DNA into a recipient bacterial strain. Again, the particles contained all the information required to produce infectious virions and the user-defined genetic cargo. While these two approaches yield preparations of particles that contained no helper bacteriophage, as they contained a self-replicating, antibiotic resistance-encoding element, there would likely be regulatory issues during commercialization. It is thus important to separate the delivered cargo from the DNA that encodes the proteins involved in the bacteriophage reproductive cycle, which is achieved with a helper bacteriophage.

The helper bacteriophage contamination problem has been addressed for M13 bacteriophage by supplying bacteriophage proteins from a plasmid that has no packaging signal, then packaging a cosmid (plasmid with a packaging signal). ${ }^{21}$ In addition, a method to produce helper bacteriophage-free transducing particles that target Staphylococcus aureus was recently developed. ${ }^{22}$ This was achieved by the reengineering of staphylococcal pathogenicity islands to remove toxin genes, and the deletion of the small terminase subunit gene from the genome of the cognate helper bacteriophage. However, the issue has not been addressed for P2 bacteriophage-based transduction.

Presented here is a method to produce pure preparations of P2 bacteriophage-based transducing particles. This is achieved by replacing the packaging signal of a P2 prophage with the delta and epsilon genes from the satellite bacteriophage P4, both under the control of an L-rhamnose-inducible promoter (Figure 1B). The delta gene product is a transcriptional activator of the P2 late genes (lysins and structural proteins), and the epsilon gene product is a derepressor of the same genes. $^{23-25}$ Thus, delta and epsilon trigger the P2 prophage to act as a helper bacteriophage (Figure 1B). This genetic manipulation simultaneously renders the late genes of the lysogen, and thus the production of transducing particles, chemically inducible and abolishes the ability of the P2 
genome to be packaged in the resulting bacteriophage particles, since the lysogen has no packaging signal. This method yields transducing particle titers of up to $1.8 \times 10^{7}$ particles $\cdot \mathrm{mL}^{-1}$ with no contamination by helper bacteriophage.

The method developed here enables for the first time the chemically induced production of transducing particles without helper P2 contamination. This could be used to deliver userdefined genetic cargo to a programmable host tropism, for a range of biotechnological purposes. This will enable the production of pharmaceutically suitable preparations, thus making it possible now to deploy P2-based transducing particles beyond the laboratory bench.

\section{RESULTS AND DISCUSSION}

Three modified prophages were created by recombineering. ${ }^{26-28}$ The prophage to which all genetic modifications were made in order to generate the mutants here was P2dell (encoded within Escherichia coli C-5545), which has the dell mutation to permit nonlethal expression of the lambda red recombinases required for recombineering (Figure 2A,B).

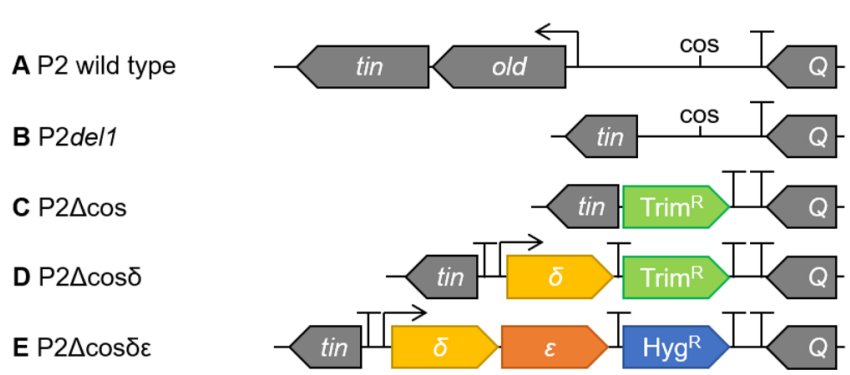

Figure 2. Relevant genotypes of bacteriophage genetic constructs. (A) Region surrounding the cos site in wild type P2 prophage. (B) The same region in dell mutant P2, which is present in Escherichia coli C5545. (C) The same region in $\mathrm{P} 2 \Delta \cos$ (encoded within Escherichia coli C-5545 $\Delta \cos$ ). (D) The same region in $\mathrm{P} 2 \Delta \cos \delta$ (encoded within Escherichia coli C-5545 $\Delta \cos \delta$ ). (E) The same region in $\mathrm{P} 2 \Delta \cos \delta \varepsilon$ (encoded within Escherichia coli C-5545 $\Delta \cos \delta \varepsilon$ ).

$\mathrm{P} 2 \Delta \cos$ (encoded within E. coli C-5545 $\Delta$ cos) (Figure $2 \mathrm{C}$ ) is a P2 prophage with the cos site replaced by a trimethoprim resistance cassette; $\mathrm{P} 2 \Delta \cos \delta$ (encoded within E. coli C-5545 $\Delta \cos \delta$ ) (Figure 2D) is the same as $\mathrm{P} 2 \Delta \cos$ but encodes $\mathrm{P} 4$ bacteriophage protein delta under the control of a rhamnoseinducible promoter; $\mathrm{P} 2 \Delta \cos \delta \varepsilon$ (encoded within E. coli C-5545 $\Delta \cos \delta \varepsilon$ ) (Figure $2 \mathrm{E}$ ) is the same as $\mathrm{P} 2 \Delta \cos \delta$, but the trimethoprim resistance cassette was replaced by $\mathrm{P} 4$ bacteriophage protein epsilon expressed in the same transcript as delta, and a hygromycin resistance cassette. The various combinations of delta and epsilon were necessary to allow their individual contributions to prophage late gene induction to be determined. Correct assembly of the strains was confirmed by Sanger sequencing.

To compare the method presented here to the method using P2vir1 as helper bacteriophage, a standard cosmid was constructed for use in both protocols, pACK57. The pACK57 cosmid was designed such that its size is an integer fraction of the size of the P2 genome, to facilitate packaging of whole multiples of pACK57 into transducing particles. (A limitation of $\mathrm{P} 2$ as a transduction vector is that transduction efficiency is optimal when the size of the transduced DNA is an integer fraction of the size of the $\mathrm{P} 2$ genome. This must thus be taken into consideration during design. A headful packaging bacteriophage would not have this limitation.) In addition, the high copy number pUC57 vector was chosen to maximize the number of cosmids available for packaging. A kanamycin resistance cassette was included to enable selection of transductants based on antibiotic resistance. Finally, the cos site from P4 bacteriophage was inserted by Gibson assembly. ${ }^{29,30}$ Construction of the cosmid was confirmed by Sanger sequencing.

As the P2vir1-derived transducing particle preparations were anticipated to contain helper bacteriophage contamination, all transduction experiments were performed using E. coli $\Delta$ rep as the recipient strain, since it is immune to P2vir1. Transduction of pACK57 to E. coli $\Delta$ rep using P2virl as the helper bacteriophage yielded $2.03 \times 10^{6} \mathrm{TFU} \cdot \mathrm{mL}^{-1}\left(s=2.9 \times 10^{5}\right.$ TFU $\cdot \mathrm{mL}^{-1} ; n=3$ ) (Figure 3 ). Transduction of pACK57 to $E$.

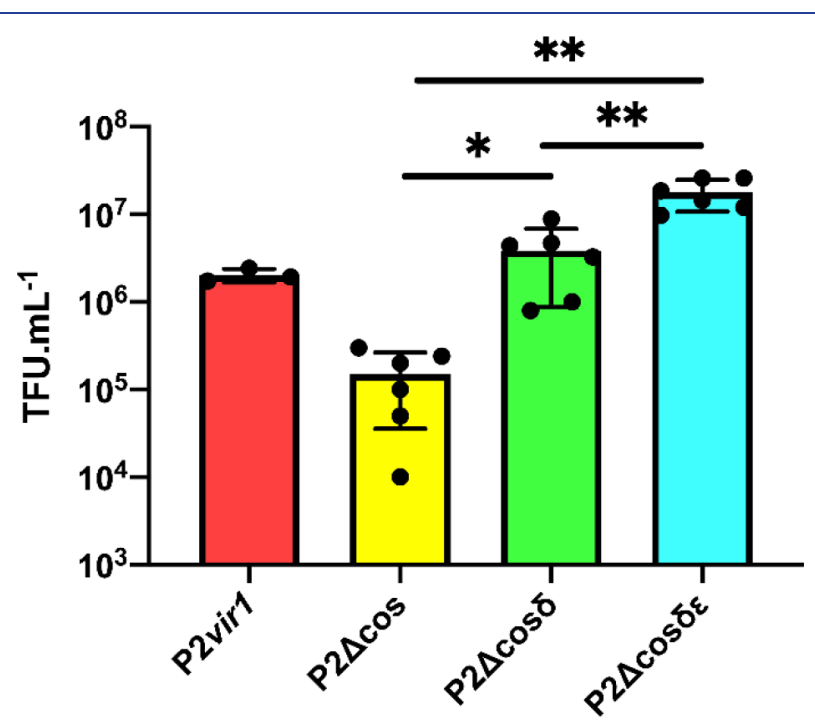

Figure 3. Comparison of transduction level with P2vir1 and $\mathrm{P} 2 \Delta \cos$ $\pm \delta \pm \varepsilon$ methods with the pACK57 cosmid and Escherichia coli $\Delta$ rep as the recipient strain. $* P \leq 0.05$. ${ }^{*} P \leq 0.01$.

coli $\Delta$ rep using $\mathrm{P} 2 \Delta \cos \delta$ as the helper bacteriophage yielded $3.85 \times 10^{6} \mathrm{TFU} \cdot \mathrm{mL}^{-1}\left(s=2.72 \times 10^{6} \mathrm{TFU} \cdot \mathrm{mL}^{-1} ; n=6\right)$ (Figure 3). Transduction of pACK57 to E. coli $\Delta$ rep using $\mathrm{P} 2 \Delta \cos \delta \varepsilon$ as the helper bacteriophage yielded $1.78 \times 10^{7}$ $\mathrm{TFU} \cdot \mathrm{mL}^{-1}\left(s=6.38 \times 10^{6} \mathrm{TFU} \cdot \mathrm{mL}^{-1} ; n=6\right)$ (Figure 3$)$. It might be reasoned that the transduction from the defective lysogen strains was due to spontaneous late gene activation, rather than expression of the $\mathrm{P} 4$ bacteriophage-derived genes. To rule this out, pACK57 was transduced to E. coli $\Delta$ rep using $\mathrm{P} 2 \Delta \cos$ as the helper bacteriophage. This yielded $1.50 \times 10^{5}$ $\mathrm{TFU} \cdot \mathrm{mL}^{-1}\left(s=1.04 \times 10^{5} \mathrm{TFU} \cdot \mathrm{mL}^{-1} ; n=6\right)$ (Figure 3$)$. This level of transduction is significantly lower than when the other defective prophages were used $(P=0.029$ when compared to $\mathrm{P} 2 \Delta \cos \delta ; P=0.0016$ when compared to $\mathrm{P} 2 \Delta \cos \delta \varepsilon)$ that encode the P4 bacteriophage-derived proteins, indicating that their expression is indeed effective in inducing the P2 bacteriophage late genes. The level of transduction when using $\mathrm{P} 2 \Delta \cos \delta$ as the helper bacteriophage was not significantly different to the level of transduction using P2vir1 $(P=0.20)$. However, the level of transduction using $\mathrm{P} 2 \Delta \cos \delta \varepsilon$ as the helper bacteriophage was significantly higher than the level of transduction when using P2vir1 $(P=0.0026)$ and significantly higher than the level of transduction when 
using $\mathrm{P} 2 \Delta \cos \delta(P=0.003)$, demonstrating the necessity of the introduction of the epsilon gene to the prophage.

To test whether the removal of the cos site from the prophage had had the intended effect of eliminating helper bacteriophage contamination, it was next necessary to assess the preparations by plaque assay (Figure 4).

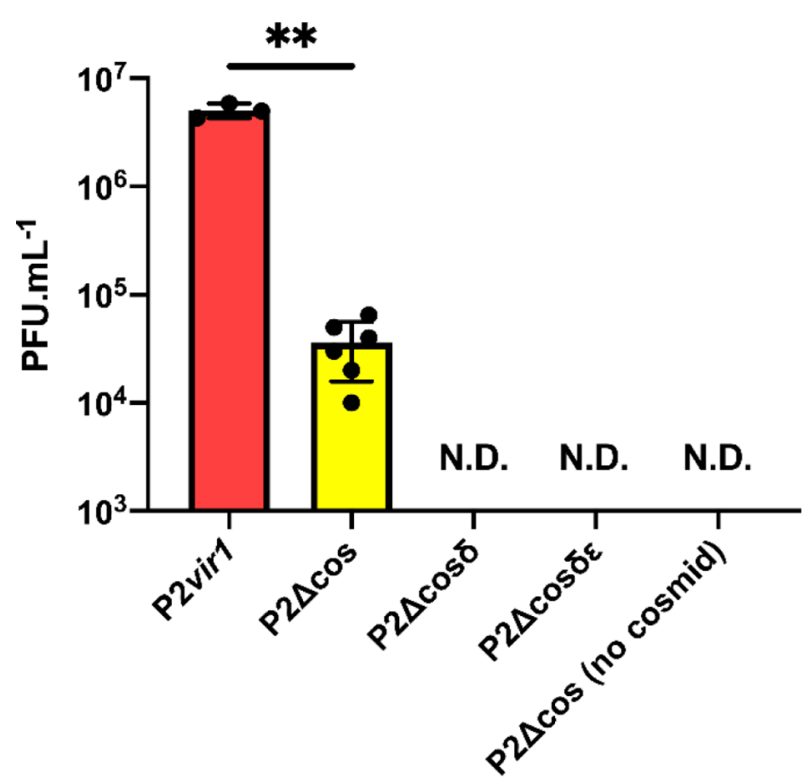

Figure 4. Plaque assays. Comparison of level of helper contamination in transducing particle preparations. The pACK57 cosmid was transduced and E. coli EMG2 was the indicator bacterial strain. $* * P$ $\leq 0.01$. N.D., not detected (lower limit of detection is $1 \mathrm{PFU} \cdot \mathrm{mL}^{-1}$ ).

To quantify the contamination by helper bacteriophage produced by the different methods, transducing particle preparations were subjected to plaque assay against the P2sensitive E. coli EMG2. This revealed $5.06 \times 10^{6} \mathrm{PFU} \cdot \mathrm{mL}^{-1}(s$ $\left.=6.4 \times 10^{5} \mathrm{PFU} \cdot \mathrm{mL}^{-1} ; n=3\right)$ in the sample prepared with P2virl as the helper bacteriophage (Figure 4). The transduction efficiency $(\%)\left(=[\mathrm{TFU} /(\mathrm{TFU}+\mathrm{PFU})] \cdot \mathrm{mL}^{-1} \times 100\right)$ when using P2virl was thus $28.7 \%(s=3.2 \% ; n=3)$ (Figure $5)$.

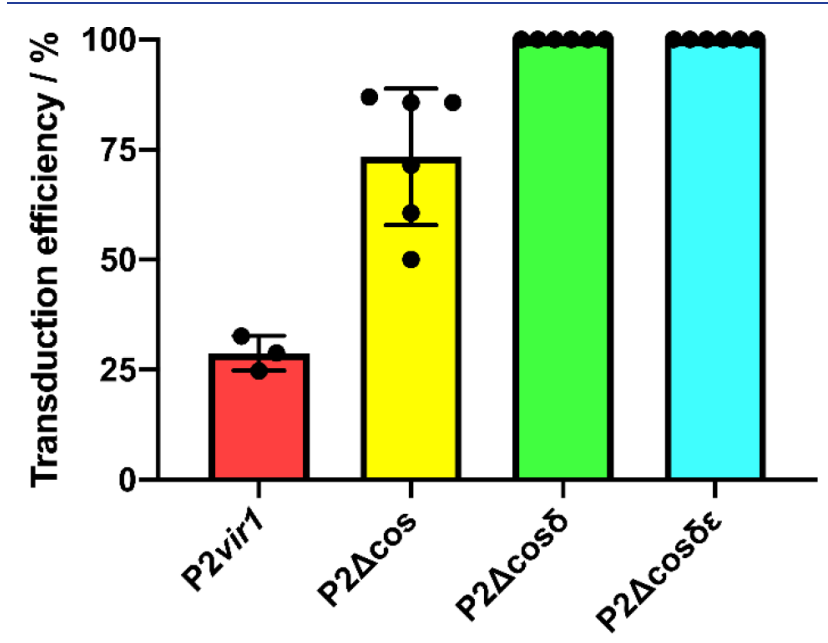

Figure 5. Comparison of transduction efficiencies of different helper bacteriophages. Transduction efficiency (\%) calculated as (TFU/ $(\mathrm{TFU}+\mathrm{PFU})) \cdot \mathrm{mL}^{-1} \times 100$.
Plaque assays of samples prepared using $\mathrm{P} 2 \Delta \cos$ as the helper bacteriophage revealed $3.6 \times 10^{4} \mathrm{PFU} \cdot \mathrm{mL}^{-1}(s=1.8 \times$ $10^{4} \mathrm{PFU} \cdot \mathrm{mL}^{-1} ; n=6$ ) (Figures 4 and 5 ). The transduction efficiency when using P2 $\Delta$ cos was thus $65.1 \%(s=30.6 \% ; n=$ 6) (Figures 4 and 5). We hypothesized that this contamination was due to reconstitution of the wild type sequence of the packaging signal of the prophage by recombination between the pACK57 cosmid and the prophage during bacterial growth. To test this, the transducing particle preparation procedure was repeated in the absence of pACK57, thus removing the substrate for homologous recombination. Plaque assays using such lysates always revealed $0 \mathrm{PFU} \cdot \mathrm{mL}^{-1}(n=6)$ (Figure 4 "P2 $\Delta \cos$ (no cosmid)"), which is consistent with our hypothesis.

Plaque assays of samples prepared using $\mathrm{P} 2 \Delta \cos \delta / \delta \varepsilon$ as the helper bacteriophage always revealed $0 \mathrm{PFU} \cdot \mathrm{mL}^{-1}(n=6)$ (Figure 4). Transduction efficiency with the newly presented method was thus $100 \%$ (Figure 5).

We further hypothesize that the absence of reconstitution of the wild type sequence of the packaging signal of the prophage, and thus the absence of plaque-forming units, when using $\mathrm{P} 2 \Delta \cos \delta / \delta \varepsilon$ might be explained by the large insertions of DNA in the former locus of the cos site. We hypothesize that the disparity in sizes of potential recombination substrates caused by the insertion of the delta/epsilon genes might reduce the efficiency of recombination to an extent that prophage reconstitution was never seen during the transducing particle production procedure.

To detect encapsidated, poorly replicative helper bacteriophage genomes, which would not be detectable by plaque assay, lysates were subjected to deoxyribonuclease (DNase) treatment, to digest DNA not contained within transducing particles, then PCR was performed to identify the packaged DNA (Figure 6). Two pairs of primers were designed: one to

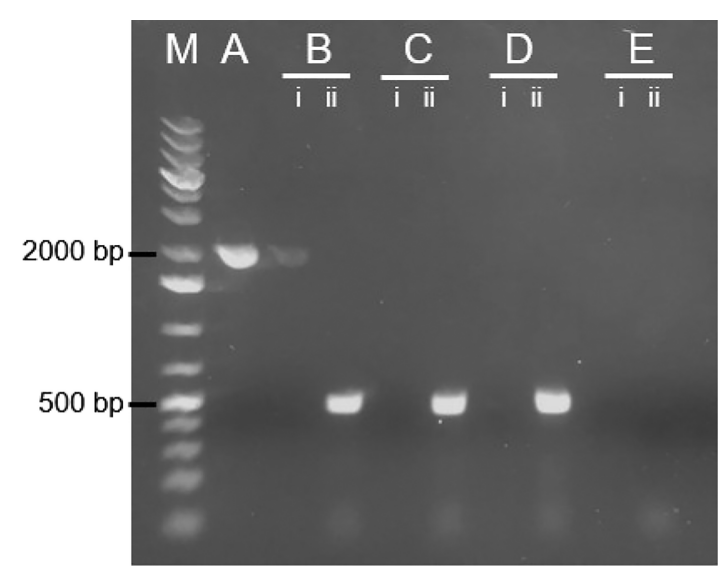

Figure 6. PCR to detect encapsidated helper bacteriophage genomes. (M) Molecular-weight size marker. (A) P2vir1 positive control performed with primers targeting P2 sequence. (B) P2 $\Delta \cos$ lysate. (C) $\mathrm{P} 2 \Delta \cos \delta$ lysate. (D) $\mathrm{P} 2 \Delta \cos \delta \varepsilon$ lysate. (E) $\mathrm{P} 2 \Delta \cos$ (no cosmid) lysate. (i) PCR performed with primers targeting P2 sequence. (ii) PCR performed with primers targeting cosmid (pACK57) sequence.

amplify a $2010 \mathrm{bp}$ region within the $\mathrm{P} 2$ genome ( $\mathrm{P} 2 \mathrm{GpH} \mathrm{F} /$ $\mathrm{R}$, Table S5); and the other to amplify a $500 \mathrm{bp}$ region within pACK57 ( $\mathrm{pk} 2$ ins F/R, Table S5), enabling distinction between the packaged DNA cargos. P2 sequence was detected only in the lysate prepared using $\mathrm{P} 2 \Delta \cos$ as the helper bacteriophage (Figure 6B). The same PCR was performed 

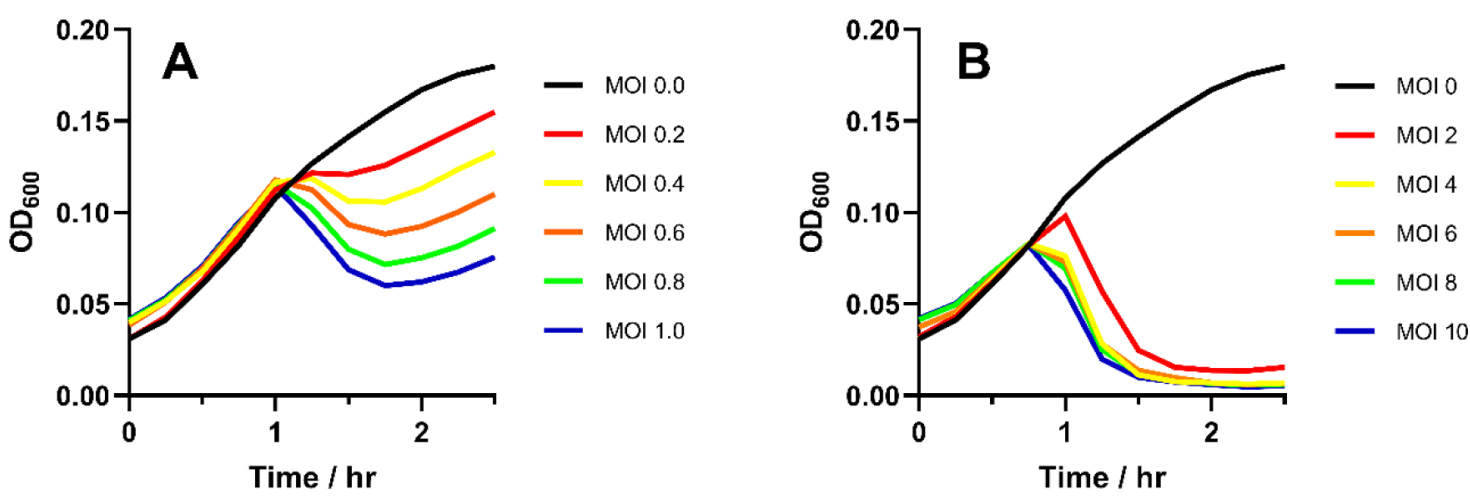

Figure 7. Delivery of lysin-encoding cosmid to bacterial cells. (A) Screen of transducing particle multiplicities of infection between 0.0 and 1.0 . (B) Screen of transducing particle multiplicities of infection between 0 and $10 . \mathrm{OD}_{600}$, optical density at $600 \mathrm{~nm}$. MOI, multiplicity of infection.

using P2virl as the template and is included as a positive control (Figure 6A). In all instances where pACK57 was intended to be present, it was detected, as indicated by the presence of a $500 \mathrm{bp}$ amplicon (Figure 6B-D). Lysates of all producer strains were positive for both $\mathrm{P} 2$ and pACK57 sequences prior to DNase treatment (data not shown), thus the absence of $\mathrm{P} 2$ sequence and presence of pACK57 sequence in the DNase-treated samples indicates that the pACK57 DNA was packaged within transducing particles. Furthermore, P2 sequence was not detected when the cosmid was excluded from the E. coli C-5545 $\Delta$ cos producer strain (Figure $6 \mathrm{E}$ ), aligned with the result of the plaque assay in Figure 4, which indicated no production of replicative bacteriophage when the cosmid was absent during production. To summarize, in lysates prepared using $\mathrm{P} 2 \Delta \cos \delta$ or $\mathrm{P} 2 \Delta \cos \delta \varepsilon$, packaged helper bacteriophage genomes were not detected by PCR, which clearly detected the cosmid, strongly suggesting the absence of encapsidated helper bacteriophage genomes.

The results presented in Figures 3-6 demonstrate that our newly developed method is capable of yielding preparations of transducing particles at titers higher than the established P2vir1-based method, ${ }^{14}$ while yielding no helper bacteriophage contamination.

To demonstrate the potential therapeutic utility of bacteriophage transduction, we sought to create an antibacterial preparation of transducing particles free of replicative helper bacteriophage. We thus designed and assembled a cosmid based upon bacteriophage P4. In this assembly, nucleotide positions 247-4065 of the genome of bacteriophage P4 (NCBI reference sequence: NC_001609.1) were replaced by a nucleotide sequence of equal size, which encodes the Escherichia phage MS2 gpL lysis protein, ${ }^{31}$ the Enterobacteria phage Phi X174 gpE lysis protein, ${ }^{32}$ and the Lambda LysS, LysR, and $\mathrm{Rz}$ lysis proteins under the control of the promoter PLtetO-1. ${ }^{33-36}$ To prevent the expression of the cosmid-encoded lysins during transducing particle production, we introduced the Marionette cluster, ${ }^{37}$ which encodes the Tet repressor, to the producer cell line by $\mathrm{P} 1$ transduction, ${ }^{38}$ repressing expression from the PLtetO-1 promoter. Since the P4-based cosmid encoded the delta and epsilon proteins of bacteriophage $\mathrm{P} 4$, we used the producer strain that does not encode these two genes, Escherichia coli C-5545 $\Delta$ cos. The cosmid was introduced to the strain by chemical transformation. The transformed cells were then capable of producing P4-based transducing particles, which in turn could infect untransformed cells of the same strain, amplifying the population of transducing particles, with no bacteriophage
P2 contamination. The resulting stock of transducing particles was then used to deliver the lysin-encoding cosmid to a culture of lysin-repression-incompetent Escherichia coli EMG2, grown to optical density at $600 \mathrm{~nm}\left(\mathrm{OD}_{600}\right)=0.2$ prior to transduction. The $\mathrm{OD}_{600}$ and thus growth and/or lysis of the transduced cells was monitored using a plate reader. A range of multiplicities of infection (MOI) was screened, from 0.2 to 1.0 in increments of 0.2 (Figure 7A), and from 2 to 10 in increments of 2 (Figure 7B). When the MOI was between 0.2 and 1.0 inclusive, the bacterial culture was noticeably lysed, with the extent of lysis correlating with the MOI, but bacterial growth promptly recovered (Figure 7A). At MOI 2, lysis was more substantial, with a less noticeable recovery (Figure 7B). When the MOI was between 4 and 10 inclusive, there was no substantial effect of MOI on the extent of lysis and no cellular recovery was observed, suggesting complete or near-complete bacterial clearance (Figure 7B). Untransduced cells (MOI 0) grew continually throughout the experiment (Figure 7). In addition, plaque assays of the transducing particle preparations, using Escherichia coli EMG2 as the indicator strain revealed no plaques, confirming that they are nonreplicative (data not shown). It was thus concluded that the lysis observed following addition of the transducing particles to the bacterial cells was due to successful delivery of the nucleic acid cargo and expression of the lysins.

The results of the experiment shown in Figure 7 thus demonstrate the potential use of a helper bacteriophage-free preparation of transducing particles as an antimicrobial agent.

\section{CONCLUSION}

We have demonstrated here a method to produce helper bacteriophage-free preparations of transducing particles, a first for bacteriophage P2. The results presented here are the first step in the development of several technologies based on the P2 virion, without using bacteriophage therapy. These technologies may include-but are not restricted to-particles that sensitize bacteria to antibiotics, particles that deliver the genetic material for the expression of antigens for the in situ production of vaccines, or particles that trigger bacteria to produce biofilm-degrading enzymes. Combined with directed evolution of the tropism-determining elements of the P2 virion, the technologies that could be produced could have very far-reaching impact indeed. 


\section{MATERIALS AND METHODS}

Strains (Bacteria and Bacteriophage). Escherichia coli C5545 and E. coli C-1a were kindly provided by Gianni Dehò, University of Milan. E. coli $\Delta$ rep was obtained from the Keio collection (Plate 29, well 12B; Keio designation: JW5604-1). ${ }^{39}$ E. coli EMG2 ATCC 23716 was purchased from the American Type Culture Collection. P2vir1 was kindly provided by Goran Jovanovic, Imperial College London. P1vir1 was kindly provided by Baojun Wang, University of Edinburgh. All bacterial/bacteriophage strains used are summarized in Tables S1 and S2. All bacterial strains original to this study will be made available via the Addgene bacterial strains repository.

Plasmids/Cosmids. The plasmid pORTMAGE- 2 was a gift from Csaba Pál (Addgene plasmid \#72677, http://n2t.net/ addgene:72677; RRID, Addgene_72677) and was used to supply lambda red recombinases during the recombineering procedure. $^{40}$ The pACK57 cosmid was constructed by Gibson assembly, $^{30}$ deriving the cos site from bacteriophage P4 (Figure S1; Table S3). ${ }^{29}$ All plasmids and cosmids original to this study will be made available via the Addgene plasmid repository.

Recombineering. To edit the genome of the P2 lysogen, recombineering was performed as published..$^{26-28}$ To eliminate lambda-P2 interference, a P2 lysogen variant was used as the strain from which all variants here were derived (Escherichia coli C-5545, which encodes the del1 mutation-the deletion of the old gene-preventing cell death upon induction of lambda proteins). ${ }^{27,28,41-45}$ Linear oligonucleotides (Table S4) were used as the recombineering substrate and were purchased from Integrated DNA Technologies.

Preparation of Transducing Particles-Prophage Used as Helper Bacteriophage. When using modified/ wild type P2 prophage as helper bacteriophage, overnight cultures of the lysogenic production strains containing the cosmid were grown at $30{ }^{\circ} \mathrm{C}$ with aeration in $1 \mathrm{~mL}$ of LuriaBertani (LB) broth supplemented with $50 \mu \mathrm{g} \cdot \mathrm{mL}^{-1}$ kanamycin (to maintain the cosmid), inoculated with glycerol stock stabs. The following day, the overnight cultures were diluted $(2 \mu \mathrm{L}$ of culture in $10 \mathrm{~mL}$ of media) in LB broth supplemented with $0.2 \%$ L-Rhamnose (to induce of $\delta / \varepsilon$ genes), $15 \mathrm{mM}$ EDTA (to prevent readsorption of transducing particles to cells or cell debris) and $50 \mu \mathrm{g} \cdot \mathrm{mL}^{-1}$ kanamycin. Cultures were grown for $24 \mathrm{~h}$ at $30{ }^{\circ} \mathrm{C}$ with aeration. Chloroform was then added to $10 \%$ final concentration. Following brief ( $\sim 5 \mathrm{~s})$ mixing by vortex, cell debris was pelleted by centrifugation at $2490 \mathrm{~g}$ for 8 min. The supernatant was aspirated with a serological pipet without disturbing the pellet and then passed through a $0.2 \mu \mathrm{m}$ syringe filter to remove remaining cells. The pellet was then discarded, and the filtered supernatant was stored at $4{ }^{\circ} \mathrm{C}$.

Preparation of Transducing Particles-P2vir1 Used as Helper Bacteriophage. When P2vir1 was used as the helper bacteriophage, published protocols were followed. ${ }^{14}$ The production strain was Escherichia coli C-1a containing the pACK57 cosmid, and LB broth was supplemented with $50 \mu \mathrm{g}$. $\mathrm{mL}^{-1}$ kanamycin.

Transductant-Forming Units (TFU) Assays. Recipient strain (Escherichia coli $\Delta$ rep) was grown overnight at $37{ }^{\circ} \mathrm{C}$ with aeration in LB. Prior to addition of transducing particles, $\mathrm{CaCl}_{2}$ was added to the overnight culture, and the culture was incubated at $37{ }^{\circ} \mathrm{C}$ with aeration for $15 \mathrm{~min}$. To $100 \mu \mathrm{L}$ of overnight culture, $100 \mu \mathrm{L}$ of transducing particle dilution were added. The mixture was mixed by inversion ( $\sim 5$ times), incubated for $10 \mathrm{~min}$ at $37{ }^{\circ} \mathrm{C}$ without aeration to allow binding of transducing particles to cells, then incubated at 37 ${ }^{\circ} \mathrm{C}$ for $30 \mathrm{~min}$ with aeration to allow for expression of antibiotic resistance proteins. The mixtures were then spread on LB agar supplemented with $50 \mu \mathrm{g} \cdot \mathrm{mL}^{-1}$ kanamycin and incubated overnight at $37{ }^{\circ} \mathrm{C}$. Transductant-forming units were enumerated the following day by counting colonies and expressed as TFU.mL ${ }^{-1}$.

Plaque-Forming Units (PFU) Assays. Plaque-forming units were enumerated by plaque assay, using Escherichia coli EMG2 as the indicator strain. To $100 \mu \mathrm{L}$ of Escherichia coli EMG2 overnight culture in LB supplemented with $5 \mathrm{mM}$ $\mathrm{CaCl}_{2}$ (to promote bacteriophage adsorption to the host), ${ }^{14}$ $100 \mu \mathrm{L}$ of lysate dilution was added. Following brief mixing (approximately two seconds on a vortex mixer), the mixture was incubated stationary at $37{ }^{\circ} \mathrm{C}$ for $10 \mathrm{~min}$. Three milliliters of soft agar (LB supplemented with $0.75 \%$ agar), melted and stored at $42{ }^{\circ} \mathrm{C}$, was added to the mixture, which was briefly mixed by swirling by hand, then poured onto an LB agar (+50 $\mu \mathrm{g} \cdot \mathrm{mL}^{-1}$ kanamycin) plate, which had been preheated to 37 ${ }^{\circ} \mathrm{C}$. The plate was swirled for even coverage by the soft agar mixture, left to solidify at room temperature for $5 \mathrm{~min}$, then incubated stationary at $37{ }^{\circ} \mathrm{C}$ overnight. Plaques were counted the following day and expressed as PFU. $\mathrm{mL}^{-1}$.

Deoxyribonuclease Treatment of Lysates. Genomic DNA in the bacteriophage lysates was digested with Deoxyribonuclease I from divine pancreas (Sigma Life Science) as per the manufacturer's instructions $(1 \mu \mathrm{L}$ of lysate; $1 \mu \mathrm{L}$ of $10 \mathrm{X}$ Buffer; $1 \mu \mathrm{L}$ of DNase; $7 \mu \mathrm{L}$ of water). Digestion was allowed to proceed for $15 \mathrm{~min}$ at $25^{\circ} \mathrm{C}$. To stop the reaction, $1 \mu \mathrm{L}$ of stop solution was added to the reaction mixtures. Finally, the DNase in the reaction mixtures was inactivated by incubating the samples at $70{ }^{\circ} \mathrm{C}$ for $10 \mathrm{~min}$. Inactivated reaction mixtures were then stored on ice until further use.

Polymerase Chain Reaction. PCR was performed using primers P2_GpH_F/R or pk2_ins_F/R (Table S5), $1 \mu \mathrm{L}$ of DNase-treated lysate as the template, and Phusion HighFidelity PCR Master Mix (Thermo Scientific), following manufacturer's instructions.

\section{ASSOCIATED CONTENT}

\section{SI Supporting Information}

The Supporting Information is available free of charge at https://pubs.acs.org/doi/10.1021/acssynbio.0c00467.

Relevant genotypes and sources of bacterial strains used; relevant genotypes and sources of bacteriophage strains used; sequence of pACK57 cosmid; sequences of linear oligonucleotides used as recombineering substrates for modification of P2 prophage; map of pACK57 cosmid; primer sequences (PDF)

\section{AUTHOR INFORMATION}

\section{Corresponding Author}

Alfonso Jaramillo - School of Life Sciences, Gibbet Hill Campus, The University of Warwick, Coventry CV4 7AL, U.K.; CNRS, Paris 75016, France; (1) orcid.org/0000-00026313-9689; Phone: +44 (0)24 765 73432;

Email: Alfonso.Jaramillo@synth-bio.org 


\section{Authors}

Matthew Tridgett - School of Life Sciences, Gibbet Hill Campus, The University of Warwick, Coventry CV4 7AL, U.K.

Maria Ababi - School of Life Sciences, Gibbet Hill Campus, The University of Warwick, Coventry CV4 7AL, U.K.; Warwick Medical School, University of Warwick, Coventry CV4 7AL, U.K.

Alexander Osgerby - School of Life Sciences, Gibbet Hill Campus, The University of Warwick, Coventry CV4 7AL, U.K.

Robert Ramirez Garcia - School of Life Sciences, Gibbet Hill Campus, The University of Warwick, Coventry CV4 7AL, U.K.

Complete contact information is available at:

https://pubs.acs.org/10.1021/acssynbio.0c00467

\section{Notes}

The authors declare the following competing financial interest(s): Prof Jaramillo and $\mathrm{Dr}$ Tridgett are listed as inventors on patent application GB2014118.0, which is based on results presented in this publication.

\section{ACKNOWLEDGMENTS}

We thank Professor Rich Calendar for many helpful discussions and ongoing support through the provision of biological samples. We thank Professor Elisabeth HaggårdLjungquist and Professor Terje Dokland for helpful discussions regarding the relationship between bacteriophages P2 and P4. We thank Professor Ramesh Wigneshweraraj and Goran Jovanovic for their continued support through helpful conversations and provision of materials. We thank Sandra Giannini and Normand Blais for many helpful discussions. This work was supported by the Biotechnology and Biological Sciences Research Council (Grant No. BB/P020615/1 [EVOENGINE] awarded to A.J.; Grant No. BB/M01116X/1 [The Midlands Integrative Biosciences Training Partnership (MIBTP)] studentship awarded to A.O.; Grant No. BB/ M017982/1 [The Warwick Integrative Synthetic Biology centre (WISB)] awarded to A.J.); The Medical Research Council (Grant No. 1936220 [Doctoral Training Partnership in Interdisciplinary Biomedical Research (MRC DTP IBR)] studentship awarded to M.A.); and the Warwick-Monash Alliance (studentship awarded to R.R.G.). We thank WISB for use of their facilities during this work. Funding for open access charge: UK Research and Innovation block grant.

\section{REFERENCES}

(1) Lederberg, J., Lederberg, E. M., Zinder, N. D., and Lively, E. R. (1951) Recombination analysis of bacterial heredity. Cold Spring Harbor Symp. Quant. Biol. 16, 413-443.

(2) Court, D. L., Oppenheim, A. B., and Adhya, S. L. (2007) A new look at bacteriophage $\lambda$ networks. J. Bacteriol. 189 (2), 298-304.

(3) Yang, H., Ma, Y., Wang, Y., Yang, H., Shen, W., and Chen, X. (2014) Transcription regulation mechanisms of bacteriophages. Bioengineered 5 (5), 300-304.

(4) Aksyuk, A. A., and Rossmann, M. G. (2011) Bacteriophage assembly. Viruses 3 (3), 172-203.

(5) Yosef, I., Goren, M. G., Globus, R., Molshanski-Mor, S., and Qimron, U. (2017) Extending the host range of bacteriophage particles for DNA transduction. Mol. Cell 66, 721-728.

(6) Bikard, D., Euler, C., Jiang, W., Nussenzweig, P. M., Goldberg, G. W., Duportet, X., Fischetti, V. A., and Marraffini, L. A. (2014)
Development of sequence-specific antimicrobials based on programmable CRISPR-Cas nucleases. Nat. Biotechnol. 32 (11), 1146-1150.

(7) Citorik, R. J., Mimee, M., and Lu, T. (2014) Sequence-specific antimicrobials using efficiently delivered RNA-guided nucleases. Nat. Biotechnol. 32, 1141-1145.

(8) Ibarra-Chávez, R., Haag, A. F., Dorado-Morales, P., Lasa, I., and Penadés, J. R. (2020) Rebooting synthetic phage-inducible chromosomal islands: one method to forge them all. BioDesign Research 2020, 5783064.

(9) Williams, S. R., Gebhart, D., Martin, D. W., and Scholl, D. (2008) Retargeting R-type pyocins to generate novel bactericidal protein complexes. Appl. Environ. Microbiol. 74 (12), 3868-3876.

(10) Nakayama, K., Takashima, K., Ishihara, H., Shinomiya, T., Kageyama, M., Kanaya, S., Ohnishi, M., Murata, T., Mori, H., and Hayashi, T. (2000) The R-type pyocin of Pseudomonas aeruginosa is related to $\mathrm{P} 2$ phage, and the F-type pyocin is related to lambda phage. Mol. Microbiol. 38 (2), 213-231.

(11) Ge, P., Scholl, D., Leiman, P. G., Yu, X., Miller, J. F., and Zhou, Z. H. (2015) Atomic structures of a bactericidal contractile nanotube in its pre- and postcontraction states. Nat. Struct. Mol. Biol. 22 (5), $377-383$.

(12) Bertani, G. (1951) Studies on lysogenesis. I. The mode of phage liberation by lysogenic. J. Bacteriol. 62, 293-300.

(13) Bertani, L. E. (1960) Host-dependent induction of phage mutants and lysogenisation. Virology 12, 552-569.

(14) Kahn, M. L., Ziermann, R., Dehò, G., Ow, D. W., Sunshine, M. G., and Calendar, R. (1991) Bacteriophage P2 and P4. Methods Enzymol. 204, 264-280.

(15) Bertani, L. E. (1968) Abortive induction of bacteriophage P2. Virology 36, 87-103.

(16) Calendar, R., Lindahl, G., Marsh, M., and Sunshine, M. (1972) Temperature-inducible mutants of P2 phage. Virology 47, 68-75.

(17) Thiel, K. (2004) Old dogma, new tricks - 21st century phage therapy. Nat. Biotechnol. 22 (1), 31-36.

(18) Chung, Y. B., and Hinkle, D. C. (1990) Bacteriophage T7 DNA packaging. I. Plasmids containing a T7 replication origin and the T7 concatemer junction are packaged into transducing particles during phage infection. J. Mol. Biol. 216 (4), 911-926.

(19) Edgar, R., Friedman, N., Molshanski-Mor, S., and Qimron, U. (2012) Reversing bacterial resistance to antibiotics by phagemediated delivery of dominant sensitive genes. Appl. Environ. Microbiol. 78 (3), 744-751.

(20) Yosef, I., Manor, M., Kiro, R., and Qimron, U. (2015) Temperate and lytic bacteriophages programmed to sensitise and kill antibiotic-resistant bacteria. Proc. Natl. Acad. Sci. U. S. A. 112 (23), $7267-7272$.

(21) Chasteen, L., Ayriss, J., Pavlik, P., and Bradbury, A. R. M. (2006) Eliminating helper phage from phage display. Nucleic Acids Res. 34 (21), e145.

(22) Ram, G., Ross, H. F., Novick, R. P., Rodriguez-Pagan, I., and Jiang, D. (2018) Conversion of staphylococcal pathogenicity islands to CRISPR-Cas9-based antibacterial drones that cure staph infections in mice. Nat. Biotechnol. 36 (10), 971-976.

(23) Halling, C., and Calendar, R. (1990) Bacteriophage P2 ogr and $\mathrm{P} 4 \delta$ genes act independently and are essential for $\mathrm{P} 4$ multiplication. $J$. Bacteriol. 172 (7), 3549-3558.

(24) Geisselsoder, J., Youdarian, P., Deho, G., Chidambaram, M., Goldstein, R., and Ljungquist, E. (1981) Mutants of satellite virus P4 that cannot derepress their bacteriophage P2 helper. J. Mol. Biol. 148, $1-19$.

(25) Liu, T., Renberg, S. K., and Haggård-Ljungquist, E. (1997) Derepression of prophage P2 by satellite phage P4: cloning of the P4 $\varepsilon$ gene and identification of its product. J. Virol. 71 (6), 4502-4508.

(26) Kuhlman, T. E., and Cox, E. C. (2010) Site-specific chromosomal integration of large synthetic constructs. Nucleic Acids Res. 38 (6), e92.

(27) Tridgett, M., Ababi, M., and Jaramillo, A. (2020) Lambda red recombineering of bacteriophage in the lysogenic state. Methods Mol. Biol. (N. Y.),. 
(28) Ababi, M., Tridgett, M., and Jaramillo, A. (2020) Scarless lambda red recombineering of bacteriophage in the lysogenic state. Methods Mol. Biol. (N. Y.),.

(29) Halling, C., Calendar, R., Christie, G. E., Dale, E. C., Dehò, G., Finkel, S., Flensburg, J., Ghisotti, D., Kahn, M. L., Lane, K. B., Lin, C.S., Lindqvist, B. H., Pierson, L. S., III, Six, E. W., Sunshine, M. G., and Ziermann, R. (1990) DNA sequence of satellite bacteriophage P4. Nucleic Acids Res. 18 (6), 1649.

(30) Gibson, D. G., Young, L., Chuang, R. Y., Venter, J. C., Hutchison, C. A., III, and Smith, H. O. (2009) Enzymatic assembly of DNA molecules up to several hundred kilobases. Nat. Methods 6, 343-345.

(31) Atkins, J. F., Steitz, J. A., Anderson, C. W., and Model, P. (1979) Binding of mammalian ribosomes to MS2 phage RNA reveals an overlapping gene encoding a lysis function. Cell 18, 247-256.

(32) Hutchison, C. A., 3rd, and Sinsheimer, R. L. (1966) The process of infection with bacteriophage phi-X174. X. Mutations in a phi-X lysis gene. J. Mol. Biol. 18 (3), 429-447.

(33) Garrett, J. M., and Young, R. (1982) Lethal action of bacteriophage lambda S gene. J. Virol. 44 (3), 886-892.

(34) Bieńkowska-Szewczyk, K., Lipińska, B., and Taylor, A. (1981) The $R$ gene product of bacteriophage Lambda is the murein transglycosylase. Mol. Gen. Genet. 184, 111-114.

(35) Young, R., Way, J., Way, S., Yin, J., and Syvanen, M. (1979) Transposition mutagenesis of bacteriophage lambda: a new gene affecting cell lysis. J. Mol. Biol. 132 (3), 307-322.

(36) Lutz, R., and Bujard, H. (1997) Independent and tight regulation of transcriptional units in Escherichia coli via the LacR/O, the TetR/O and AraC/I1-I2 regulatory elements. Nucleic Acids Res. 25 (6), 1203-1210.

(37) Meyer, A. J., Segall-Shapiro, T. H., Glassey, E., Zhang, J., and Voigt, C. A. (2019) Escherichia coli "Marionette" strains with 12 highly optimized small-molecule sensors. Nat. Chem. Biol. 15, 196-204.

(38) Thomason, L. C., Costantino, N., and Court, D. L. (2007) E. coli genome manipulation by $\mathrm{P} 1$ transduction. Curr. Protoc. Mol. Biol., 1.17.1.

(39) Baba, T., Ara, T., Hasegawa, M., Takai, Y., Okumura, Y., Baba, M., Datsenko, K. A., Tomita, M., Wanner, B. L., and Mori, H. (2006) Construction of Escherichia coli K-12 in-frame, single-gene knockout mutants: the Keio collection. Mol. Syst. Biol. 2, 1-11.

(40) Nyerges, Á., Csörgő, B., Nagy, I., Bálint, B., Bihari, P., Lázár, V., Apjok, G., Umenhoffer, K., Bogos, B., Pósfai, G., and Pál, C. (2016) A highly precise and portable genome engineering method allows comparison of mutational effects across bacterial species. Proc. Natl. Acad. Sci. U. S. A. 113 (9), 2502-2507.

(41) Lindahl, G., Sironi, G., Bialy, H., and Calendar, R. (1970) Bacteriophage lambda; Abortive infection of bacteria lysogenic for phage P2. Proc. Natl. Acad. Sci. U. S. A. 66 (3), 587-594.

(42) Brégégère, F. (1974) Bacteriophage P2- $\lambda$ interference: Inhibition of protein synthesis involves transfer RNA inactivation. $J$. Mol. Biol. 90 (3), 459-467.

(43) Brégégère, F. (1976) Bacteriophage P2- $\lambda$ interference: II. Effects on the host under the control of lambda genes $\mathrm{O}$ and P. J. Mol. Biol. 104 (2), 411-420.

(44) Brégégère, F. (1978) Bacteriophage P2- $\lambda$ interference: III. Essential role of an early step in the initiation of lambda replication. $J$. Mol. Biol. 122 (2), 113-125.

(45) Bertani, G. (1975) Deletions in bacteriophage P2. Circularity of the genetic map and its orientation relative to the DNA denaturation map. Mol. Gen. Genet. 136, 107-137. 